\title{
Tecnologias e Modos de ser no contemporâneo
}

\author{
Dolores Galindo
}

Universidade Federal de Mato Grosso, Cuiabá, MT, Brasil.

\begin{abstract}
Sim. Se você apanha um lenço e o estende para passá-lo, você pode definir sobre ele distâncias e proximidades fixas. Em torno de um pequeno círculo que você desenha próximo a um lugar, você pode marcar pontos próximos e medir, pelo contrário, distâncias longínquas. Tome em seguida o mesmo lenço e amasse-o, pondo-o em seu bolso: dois pontos bem distantes se vêem repentinamente lado a lado, até mesmo superpostos; e se, além disso, você rasgar em certos lugares, dois pontos próximos podem ser afastar bastante (Serres, 1999, p.82).
\end{abstract}

Tecnologias e modos de ser no contemporâneo, coletânea organizada por Solange Jobim e Marcia Moraes, publicada em 2010, reúne reflexões iniciadas, dois anos antes, durante encontro do GT Cotidiano e Práticas Sociais da Associação Nacional de Pesquisa e Pós-Graduação em Psicologia (ANPEPP). Além das organizadoras, assinam o trabalho André Werneck Barroin, Benedito Medrado, Betina Hillesheim, Jefferson Bernardes, Henrique Caetano Nardi, Lílian Rodrigues Cruz, Marcos Reigota, Mary Jane Spink, Milagros Garcia Cardona, Neuza Guareschi, Ricardo Pimentel Méllo,
Ronald Arendt, Rosineide Cordeiro, Simone Hüning e Vera Menegon.

Pela presença do termo contemporâneo no título não se compreenda que os autores e autoras versam sobre o que há de mais recente nas tecnologias e modos de ser. O traço genealógico que risca boa parte dos dez capítulos não permite esta leitura. Alguns temas, como as noções de Natureza, exploradas por Marcos Reigota, no capítulo Natureza, Tecnociências e Educação, por exemplo, possuem lastro antigo na Filosofia.

O sentido atribuído ao contemporâneo na obra se aproxima de uma acepção topológica na qual não é a novidade ou o fato de ser recente, o que faz de um tema contemporâneo. Retomemos Michel Serres que no texto em epígrafe com uma imagem simples, a de um lenço, propõe que qualquer coisa pode tornar-se contemporânea de outra, não havendo distâncias temporais e espaciais definitivas entre elas.

As temáticas abordadas nos capítulos da coletânea têm como marca a 
heterogeneidade e o fato de serem vias de acesso a problemáticas que são focos de experiência importantes em nossa cultura. Elenquemo-nas: Educação Ambiental e currículo; Álbuns de bebês; Deficiência Visual; Diversidade sexual; Sistema de cotas nas Universidades Brasileiras; Novas biotecnologias e mutações nas subjetividades; Lei Maria da Penha; Previdência Social e gênero no sertão de Pernambuco; Tecnologias de reprodução assistida; Literatura infantil. No sumário, os capítulos são dispostos sem divisão em partes ou blocos. O livro não forma um edifício, por isso, optamos pela imagem do lenço, emprestada a Michel Serres, para falar sobre ele.

Ao evocarmos a imagem de um lenço, lidamos com tecidos. Assim, cabe perguntar: haveria uma costura entre os capítulos? Na apresentação da coletânea, a proposta de ligação entre os capítulos se dá pela existência de dois eixos temáticos em torno dos quais se articulariam os textos. Um primeiro, nomeado tecnologias como governamentalidade, voltado às discussões sobre saber-poder na tradição foucaultiana e um segundo, tecnologias como materialidades, cujo diálogo seria, sobretudo, com os estudos em Ciência, Tecnologia e Sociedade (CTS). Para efeito desta resenha, tomaremos como fios, os eixos propostos pelas organizadoras do trabalho.
Abordemos os capítulos que enfatizam o eixo tecnologias como materialidades. Márcia Moraes e Ronald Arendt, em Materialidade e socialidades no cotidiano: múltiplos modos de ordenamento da deficiência visual, estudam maneiras pelas quais a cegueira adquire existência. Discorrem sobre ordenamentos provisórios que produzem multiplicidades e sobre possíveis políticas ontológicas não normalizadoras. Os autores situam a pesquisa "na esteira daquelas empreendidas por Foucault (1972, 1987, 2000) e, posteriormente, pelo campo de estudos chamados CTS Ciência, Tecnologia e Sociedade" (p. 53), diferenciando-a das vertentes construcionistas que caracterizam boa parte dos estudos interdisciplinares sobre deficiência por manterem dicotomias entre natural e social. Em Políticas públicas e educação superior: o jornal como ator social, André Barroin e Solange Jobim exploram o jornal como ator social no debate sobre sistema de cotas no Brasil. Os autores tomam o jornal como actante que faz existir realidades. Diferentemente do capítulo que comentamos anteriormente no qual há um movimento mais claro de diferenciação dos estudos construcionistas aos quais se reconhece débito quanto à desnaturalização das deficiências, André Barroin e Solange Jobim localizam seu trabalho no campo dos estudos em CTS 
conjugando-o a métodos de análise em práticas discursivas.

No eixo tecnologias como governamentalidade caracterizado por leituras foucaultianas e pós-foucaultianas, situamos cinco dos capítulos. Em Políticas públicas, governamentalidade $e$ Diversidade Sexual: as tecnologias da educação como campo de investimentos $e$ inflexão do dispositivo da sexualidade, Henrique Nardi, discute a rede enunciativa que atravessa projetos de educação para a diversidade na escola. Apoiado, sobretudo, na noção foucaultiana de dispositivo, o autor permite entrever os limites de noções como homofobia por sua vinculação com políticas identitárias que, de maneira onipresente, marcam os debates na área. Também tomando como fulcro a noção de dispositivo, desta vez, com contornos mais deleuzianos, Rosineide Cordeiro e Milagros Cardona, no capítulo $A$ Previdência Social e a constituição de modos de ser mulher trabalhadora rural no Sertão de Pernambuco discutem as linhas de visibilidade e enunciação produzidas nas vestimentas, unhas, gestos e outras marcas corporais de mulheres que acessam o benefício da previdência social. Com o sugestivo título Ligeiramente humana: novas biotecnologias $e$ experiências de si no contemporâneo, Simone Huning e Neuza Guareschi constroem um texto que mescla notícias de jornal, recentes descobertas científicas e anúncios de cosméticos, dentre outros aportes, para discutir como novas biotecnologias se articulam a modos de ser e, principalmente, como a Psicologia pode contribuir à produção de perspectivas críticas e não fatalistas sobre o tema.

Ainda no eixo tecnologias como governamentalidade, no capítulo Literatura Infantil como tecnologia de governo da Infância, Betina e Lílian Cruz discutem como a adjetivação infantil conferida a algumas obras literárias e a sua pedagogização estão articuladas ao governo dos infantis. Por fim, em Dispositivo legal como tecnologia de governo da vida: usos e efeitos da Lei Maria da Penha, Ricardo Méllo, Benedito Medrado e Jefferson Bernardes estudam tecnologias postas em funcionamento com a Lei Maria da Penha, desnaturalizando leituras mais simplistas baseadas na defesa acrítica do caráter inclusivo e universal de dispositivos legais.

Dois capítulos do livro emaranham os eixos-fios Tecnologias como governamentalidade e tecnologias como materialidades. Mary Jane Spink, em Álbuns de Bebê: reflexões sobre tecnologias que performam pessoalidades, aborda tecnologias como "materialidades relacionais com efeitos de governamentalidade". Afirma que álbuns de bebês transitam entre o registro 
biográfico (prazer de lembrar) e estratégias disciplinares e biopolíticas (cuidado infantil), atuando como tecnologias de individuação e produção do que nomeia "pessoalidades". Neste capítulo, a autora faz questão de apontar a materialidade relacional dos estudos em Ciência, Tecnologia e Sociedade como uma alternativa à ênfase lingüística característica das pesquisas construcionistas. Dá continuidade ao uso da noção de práticas discursivas e diminui a ênfase na produção de sentidos, como pontua ela "Há algum tempo, as pesquisas desenvolvidas no grupo práticas discursivas e produção de sentidos vêm buscando reconfigurar o foco linguístico, e um aspecto central dessa proposta teóricometodológica foi adotar a noção de materialidades relacionais (p. 48)" No capítulo intitulado Tecnologias em Saúde reprodutiva: implicações nos modos de ser contemporâneos, Vera Menegon argumenta que tecnologias (definidas por ela como composições sociotécnicas) imbricam-se a materialidades, socialidades e governamentalidade. Diferentemente de Mary Jane Spink que conserva a dimensão das práticas discursivas com menor ênfase na produção de sentidos, a autora destaca a importância da produção de sentidos, integrando a materialidade relacional como uma ampliação do escopo abrangido pelos estudos desenvolvidos nessa vertente.
Escreve ela: "Reafirmamos a centralidade das práticas discursivas para a produção de sentidos, mas ampliamos a rede de conexões, destacando a produção de materialidades no fazer de socialidades e estratégias de governo" (p. 238).

Aproximações entre estudos em biopolítica e pesquisas em Ciência, Tecnologia e Sociedade (CTS) vêm sendo objeto de recentes reflexões feitas em um campo e em outro.

Num texto de revisão sobre os estudos em governamentalidade, Rose, O’ Maylley e Valverde (2006) identificam, pelo menos, três pontos de convergência entre estes e os trabalhos em CST. Primeiro, a rejeição aos hábitos estruturalistas de pensamento em favor de estudos detalhados sobre como saberes e outros recursos são mobilizados e transformados em determinadas redes. Segundo, uma postura agnóstica que ao invés de buscar porquês e interesses, estuda os processos de produção de algo. Terceiro, um anti-humanismo que recusa o privilégio do homem e dos grandes eventos, considerando a importância que objetos, técnicas e tecnologias podem desempenhar. Destacam que os estudos em CTS dedicam maior espaço à teorização sobre a agência objetual do que os trabalhos apoiados na noção de governamentalidade. 
Tirado (2010), falando a partir do campo dos estudos em CTS, também reconhece que o encontro entre as pesquisas em CTS e os trabalhos em biopolítica é fértil e saudável. Para ele, o encontro traria aos estudos em biopolítica uma menor generalidade e às explicações em CTS noções alternativas às de cosmopolíticas e ecologias políticas. Pontua ele: "Penso que um cosmos comum que habitamos conjuntamente é mais do que um tipo de cosmopolítica. (...). É, em realidade, um mundo ou um modo de habitar biopolítico (s/p., tradução nossa)".

Recuperando o histórico do Grupo de Trabalho Cotidiano e Práticas Sociais do qual deriva a coletânea, percebemos que o encontro entre estudos em CTS e em governamentalidade se articula a uma maior ênfase na dimensão performativa, efeitos, e menor destaque à dimensão discursiva, produção de sentidos, que caracteriza os pós-construcionismos (Iñiguez, 2004). As condições de emergência do encontro entre os campos de estudo se vinculam, também, às diásporas que tornaram conceitos e métodos, antes restritos aos pesquisadores em CTS, atravessamentos inevitáveis para pensar sobre modos de vida e tecnologias (Callén e cols., 2011). É nesse contexto que percebemos uma segunda inflexão performada pela publicação da coletânea, o encontro entre pesquisadores brasileiros em CTS e em Práticas Discursivas e Produção de Sentidos. No Brasil, os pesquisadores e pesquisadoras, de um e outro campo, apesar das várias convergências, não haviam ainda se desafiado a uma publicação derivada de sessões de conversas e reflexões coletivas.

Pelas considerações expostas, Tecnologias e Modos de Ser no Contemporâneo é uma leitura imprescindível para pesquisadores que encontram no livro uma reflexividade franca e tecido para outras dobras. $\mathrm{Na}$ coletânea, somos instados a pensar sobre os modos de vida na Psicologia Social. Se até aqui usamos a imagem simples do lenço roubada a Serres, recordemos que ele foi o primeiro acadêmico a tomar posse na Academia Francesa de Ciências numa cerimônia sem espadas. Instigante provocação a pesquisar e trabalhar por uma Psicologia Social sem trincheiras, sem espadas, sem igrejas (Ibañez, 2006).

\section{Referências}

Callém, B., Domènech, M., Lopez, D., Rodríguez, I., Sanchez-Criado, T. e Tirado, F. Diásporas y transiciones en la Teoría Del Actor-Red. Athenea Digital, 11(1), 3-13.

Ibañez, T. (2007). Invitación al deseo de un mundo sin iglesias, alias, 
variaciones sobre el relativismo.

Fermentum, 17, 50, 535-546.

Iñiguez, L. (2004). La Psicología Social en la encrucijada postconstruccionista: historicidad, subjetividad, performatividad, acción. In: Guareschi, N. (Org.) Estratégias de Invenção do Presente: a Psicologia Social no contemporâneo (pp. 1553). Porto Alegre: EDIPUCRS.

Rose, N., O’Malley, P. e Valverde, M. (2006). Governmentality. Annu. Rev. Law. Soc. Sci., 2, 83-104.

Serres, M. (1999) Luzes: cinco entrevistas com Bruno Latour. São Paulo: Unimarco Editora.

Tirado, F. Teoria Ator-Red y Biopolitica. Trabalho apresentado no I Encuentro ANT: presente y futuro de la teoría del actor-red. Barcelona. Disponível em:

http://network2matter.wordpress.com biopolitica/. Acessado em: 14/03/2011.

Dolores Galindo possui graduação em Psicologia pela Universidade Federal de Pernambuco (UFPE), mestrado e doutorado em Psicologia Social pela Pontifícia Universidade Católica de São Paulo (PUCSP). É Professora do Programa de Pós-Graduação Interdisciplinar (Mestrado) em Estudos de Cultura Contemporânea e do curso de graduação em Psicologia da Universidade Federal de Mato Grosso.

\section{Endereço para correspondência:}

Universidade Federal de Mato Grosso UFMT. Instituto de Linguagens / ECCO Av. Fernando Corrêa da Costa, no 2367, sala 44/IL. Bairro Boa Esperança, CuiabáMT - 78060-900.

Email: doloresgalindo@ufmt.br 